\title{
Discrimination Probes for Evaluating Learning of Emergent Name-Object Relations by Exclusion
}

\author{
Leylanne Martins Ribeiro de Souza*,1 \\ Orcid.org/0000-0002-6175-3183 \\ Maria Stella Coutinho de Alcantara Gil ${ }^{1}$ \\ Orcid.org/0000-0003-4375-3232 \\ Lucas Tadeu Garcia ${ }^{1}$ \\ Orcid.org/0000-0003-2897-9356
}

${ }^{1}$ Universidade Federal de São Carlos, São Carlos, SP, Brasil

\begin{abstract}
Responding by exclusion is a robust response pattern; however, regular occurrence of responses that attest the name-object conditional relation does not correspond to consistent learning of the relation. This study aimed to evaluate learning of name-object relations, after emergence of the conditional relation in responding by exclusion, through discrimination probes presented to 19 children between 14 and 25 months old. Familiar name-object conditional stimuli were taught as baseline. Control, exclusion, and discrimination probes found control by stimulus novelty, emergence of name-object relation, and learning of emergent relation, respectively. If the learning of the emergent relation did not occur, the teaching by exclusion was inserted. Six participants responded by exclusion. Discrimination probes attested learning of two name-object relations by three participants. One participant's responses were consistent with learning two relations after teaching of emergent name-object relations. Discrimination probes were found to be an effective measure for learning of emergent name-object relations by small children.
\end{abstract}

Keywords: Responding by exclusion, learning by exclusion, discrimination probes, children.

\section{Sondas de Discriminação na Avaliação da Aprendizagem de Relações Emergentes Nome-Objeto por Exclusão}

\section{Resumo}

O responder por exclusão é um padrão de resposta robusto, entretanto, a ocorrência regular da resposta que atesta a relação condicional nome-objeto não corresponde à aprendizagem consistente da relação. Este estudo visou avaliar a aprendizagem de relações nome-objeto, após a emergência da relação

* Mailing address: Universidade Federal de São Carlos, Departamento de Psicologia, Centro de Educação e Ciências Humanas, Jardim Guanabara, São Carlos, SP, Brazil 13565-905. Caixa-postal: 676. Phone: (16) 3351-8493. E-mail: leylannemrs@yahoo.com.br, dpsi.stellagil@gmail.com and lucas.uai@gmail.com Support: Coordenação de AperfeiçoamentodePessoaldeNívelSuperior(CAPES), processo 88887.136407/201700; Conselho Nacional de Desenvolvimento Científico e Tecnológico (CNPq), processo 465686/2014-1; e Fundação de Amparo à Pesquisa do Estado de São Paulo (FAPESP), processo 2014/50909-8, em apoio ao Instituto Nacional de Ciência e Tecnologia sobre Comportamento, Cognição e Ensino (INCT-ECCE). 
condicional no responder por exclusão, empregando sondas de discriminação as quais foram expostas 19 crianças, entre 14 e 25 meses. Discriminações condicionais nome-objeto com estímulos familiares foram ensinadas para compor a linha de base. Sondas controle, de exclusão e de discriminação verificaram respectivamente o controle pela novidade dos estímulos, a emergência da relação nomeobjeto e a aprendizagem da relação emergente. Se não ocorresse a aprendizagem da relação emergente, inseria-se o ensino por exclusão. Seis participantes responderam por exclusão. Sondas de discriminação atestaram a aprendizagem de duas relações nome-objeto para três participantes. Um participante respondeu consistentemente com a aprendizagem de duas relações, após o ensino da relação nomeobjeto emergente. As sondas de discriminação constituíram-se em medida efetiva da aprendizagem de relações emergentes nome-objeto por crianças pequenas.

Palavras-chave: Responder por exclusão, aprendizagem por exclusão, sondas de discriminação, crianças.

\section{Pruebas de Discriminación en la Evaluación del Aprendizaje de Relaciones Emergentes Nombre-Objeto por Exclusión}

\section{Resumen}

La respuesta por exclusión es un patrón de respuesta robusta. Sin embargo, la ocurrencia regular de la respuesta que da cuenta de la relación condicional nombre-objeto no se corresponde al aprendizaje consistente de dicha relación. Este estudio tuvo como objetivo evaluar el aprendizaje de relaciones nombre-objeto, después de la emergencia de la relación condicional al responder por exclusión, utilizando ensayos de prueba de discriminación a las cuales fueron expuestos 19 niños, de entre 14 y 25 meses. Discriminaciones condicionales nombre-objeto con estímulos familiares se enseñaron para constituir la línea base. Las pruebas de control, exclusión y discriminación verificaron, respectivamente, el control por novedad de los estímulos, la emergencia de la relación nombre-objeto y el aprendizaje de la relación emergente. Si no ocurría el aprendizaje de la relación emergente, se inserta la enseñanza por exclusión. Seis participantes respondieron por exclusión. Las pruebas de discriminación mostraron el aprendizaje de las relaciones nombre-objeto para tres participantes. Un participante respondió consistentemente con el aprendizaje de dos relaciones, después de la enseñanza de la relación nombre-objeto emergente. Las pruebas de discriminación se constituyeron como una medida efectiva del aprendizaje de relaciones emergentes nombre-objeto para niños pequeños.

Palabras clave: Responder por exclusión, aprendizaje por exclusión, pruebas de discriminación, niños.

Responding by exclusion means the choice of a stimulus based on the rejection of another stimulus, or stimuli. In the context of research on vocabulary acquisition, the term has been used to refer to the choice of an undefined object or referent in relation to a sample (e.g., a word) which is also undefined, when the latter is present simultaneously with one or other defined stimuli. This pattern of choice has been consistently documented in the experimental literature, both in humans and in animals (e.g., Dixon, 1977; Wilkinson, Dube, \& Mcllvane, 1998). The expression "defined stimulus" refers to stimuli (sample or comparisons) whose relationship with another stimulus has been established within or outside the experimental context; 'undefined stimulus' means stimuli not previously related to any other stimulus. A novel stimulus, in turn, refers to those stimuli with which the participants have never interacted, or which are being presented for the first time during the experiment.

An important subject of research in the area, however, arises from an inconsistency in which, in the exclusion trial a new control stimulus relation emerges (the undefined sample establishes 
the undefined comparison as the correct choice), whereas in later trials this control of stimulus is not maintained (i.e. when the sample is presented again, the subject may choose a different stimulus, in its presence). Especially in relation to learning of words or of auditory-visual relationship (e.g., name-object or name-figure), recent studies with small children (aged 18 to 36 months) have indicated that a single exposure to exclusion trials is rarely sufficient for the participants to learn the new relation (Domeniconi, Costa, de Souza, \& de Rose, 2007; Horst \& Samuelson, 2008; Ribeiro de Souza, Gil, \& Garcia, 2018; Ribeiro de Souza, Minto de Sousa, \& Gil, 2016; Schmidt, Franco, Lotério, \& Gomes, 2016).

To investigate what has been called 'learning by exclusion', in matching-to-sample tasks, researchers have used a procedure in which, after the teaching of conditional baseline discriminations, the participants are exposed to exclusion probes, in which an undefined sample is presented and the participant has to choose an undefined stimulus which is presented simultaneously with one or more defined comparison stimuli. In the case of choice of the undefined stimulus, evaluation of the learning of the relationship between undefined sample and comparison is then conducted immediately, usually through different types of learning probes (cf. Costa, Domeniconi, $\&$ de Souza, 2014).

In the seminal study by Dixon (1977), for example, after the participants (adolescents with intellectual disability) having consistently chosen the letters upsilon and theta in relation to their respective names, by exclusion, they were presented with probes in which only the two letters and their names alternated with comparisons and samples, respectively. The author called these probes 'discrimination trial probes'. In that study, in spite of the consistency of the choice by exclusion, only two of the eight participants presented a performance consistent with learning for the first group of stimuli (Greek letters). For the other groups, the participants presented a consistent performance: six of the eight participants achieved the criterion for the second group, of Japanese letters; and in the third group, of Greek letters, six participants scored above the criterion established in the pre-test and the other two participants achieved the criterion.

To investigate the factors that influenced both the choice by exclusion and also the performance in learning probes, some authors developed various arrangements of trials designed to make it possible to evaluate the stimulus control topographies for the responses of the participants in the tasks (Wilkinson \& McIlvane, 1997). For this, one of the resources most used was insertion between the comparison stimuli of the so-called blank comparison, or mask, which makes it possible, for example, to evaluate whether the choice by exclusion takes place even in the absence of a novel undefined stimulus (Costa, Wilkinson, McIlvane, \& de Souza, 2001). The mask may be designated as an incorrect choice, or a correct one (when it substitutes the stimulus related to the sample presented) in a trial, and allows rejection of all the other stimuli presented. In this procedure, the mask makes it possible to identify experimental control of the effects of choice by the new event, or preference for a stimulus.

Costa et al. (2014) described the four principal types of learning probes used in these studies on exclusion. These probes have the function of evaluating whether the control of the choice of undefined stimulus in relation to the same sample is maintained in later situations, in which the parameters which made the exclusion possible are no longer present. The evaluations may require that the individual once again selects the stimulus in relation to the same sample presented previously, in the context of novel stimuli or distractors, or, further, that the individual rejects the stimulus chosen in the exclusion probe, establishing a new exclusion relation.

In learning probe 1 (sample: novel undefined stimulus; comparisons: defined stimulus, undefined present in the exclusion, and mask), the correct choice depends on rejection of the stimulus chosen in the exclusion probe in relation to the novel sample stimulus and the defined stimulus, resulting in the choice of the mask. In learning probe 2 (sample: novel undefined stimulus; comparisons: undefined stimulus present in 
the exclusion, novel undefined, and masked), the correct choice will take place based on the selection of a novel undefined comparison stimulus in relation to a novel sample, and also of rejection of the mask and the stimulus chosen in the exclusion probe. In learning probe 3 (sample: undefined stimulus present in the exclusion; comparisons: defined stimulus, novel undefined stimulus and mask), the participant must reject a defined stimulus and a novel undefined stimulus in relation to the sample of the exclusion probe, choosing the mask. Learning probe 4 (sample: undefined stimulus present in the exclusion; comparisons: undefined stimulus present in the exclusion, novel undefined stimulus, and mask), the correct choice has to be made based on the selection of the undefined stimulus chosen in the exclusion probe in relation to the corresponding sample, and the rejection of a novel undefined stimulus of the mask.

These probes, often used in different combinations to assess learning, produced important results to clarify the sources of control of stimulus that produce responses and learning by exclusion that are consistent, in children from age 24 months (Costa et al., 2001; Wilkinson \& McIlvane, 1997). Based on the criterion of successes in at least three of the probes, the evidences of learning in children below the age of 36 months after only one choice by exclusion has been scarce (Antoniazzi, Domeniconi, \& Schmidt, 2014; Barbosa, Gomes, Costa, \& Schmidt, 2015; Domeniconi et al., 2007; Ribeiro, Gallano, Souza, \& de Souza, 2016; Ribeiro de Souza et al., 2016; Schmidt et al., 2016).

These challenging results have justified the hypothesis as to which factors lead to rapid learning of novel conditional relations or, more specifically, of novel words. Some factors would be related to the characteristics of the participants, such as age, or size of vocabulary; others refer to aspects of the procedure - for example the number of exclusion trials, or the type of activity (Bion, Borovsky, \& Fernald, 2013; Horst \& Samuelson, 2008; Langsdorff, Schmidt, \& Domeniconi, 2015; Schmidt et al., 2016). However, some results suggest that the performance of younger children could be related to certain characteristics of the arrangements of comparison stimuli in the traditional learning probes (Ribeiro de Souza et al., 2018; Schmidt et al., 2016), such as, for example, control by rejection.

The main factor that sustains this argument is that some probes (for example, probes with control by rejection) have produced a larger proportion of errors than others. The trials in which the participants errors most are those that require rejection of the newest undefined comparison stimuli - type 3 and 4 probes (cf. Costa et al., 2014; Ribeiro de Souza et al., 2016; Schmidt et al., 2016). Although the arrangement that makes possible the rejection of newer undefined stimuli is important for ensuring that new relation learned is evaluated based on different stimulus control topographies, strengthening the parameters for inference of learning, it is possible that a bias of choice based on novelty could affect the results observed. Some evidences on the choice patterns of children in situations of learning name-object relations point in this direction (cf. Horst, Samuelson, Kucker, \& McMurray, 2011).

If the arrangement of stimuli in the learning outcome trials can increase the probability of errors by the participants, then the negative evidences on learning by exclusion in small children could be being produced by the methods of evaluation used, especially as a function of control by novelty arising from insertion of novel undefined stimuli in the probes. Consequently, it is important to evaluate whether other methodologies produce different results. One alternative would be to employ the discrimination probes used in many of the initial studies on exclusion responding (e.g., Carr, 2003; de Rose, de Souza, \& Hanna, 1996; de Rose, de Souza, Rossito, \& de Rose, 1989; Dixon, 1977; McIlvane \& Stoddard, 1981). In discrimination probes, learning by exclusion is evaluated in trials in which only the stimuli presented in the exclusion trials alternate as samples and comparisons. Another alternative would be to use additional measures that could serve as indication of learning, such as the naming responses emerging from choice by 
exclusion (e.g., Costa, Grisante, Domeniconi, de Rose, \& de Souza, 2013). Even though, especially for small children, the emergence of naming responses does not necessarily take place after learning by exclusion (Costa et al., 2013; Greer \& Du, 2015; Ribeiro et al., 2016), its occurrence presumably suggests that the name-object relation has been learned.

Thus, this study aimed to evaluate learning by exclusion of relations between names and objects through discrimination probes (Dixon, 1977), after the emergence of the conditional relation in the response by exclusion, in 19 participants aged between 14 and 25 months. Also, it aimed to evaluate whether the positive results in these probes corresponded to the positive results in two other types of methodologies of evaluation of learning by exclusion: three learning probes (Types 1, 3 and 4) commonly used in the literature of the area (e.g., Costa et al., 2014), and naming probes (Costa et al., 2013).

\section{Method}

\section{Participants}

The participants were 19 children aged between 14 and 25 months at the beginning of the experiment (10 boys and 9 girls) recruited in a day-care center.

\section{Instruments}

The initial and final repertory of the children was evaluated using two instruments. The Denver II Developmental Screening Test (Frankenburg, Dodds, Archer, \& Bresnick, 1990; version translated and adapted for use in Portuguese by Pedromônico, Bragatto, \& Strobilus, 1999), and the Inventário Portage Operacionalizado - IPO ("Portage Checklist"; Bluma, Shearer, Frohman, \& Hilliard, 1976, version translated and adapted to Portuguese by Williams \& Aiello, 2001). The two instruments employed produced the repertory of children as from aged 0 months, and enabled reapplication month-by-month.

\section{Materials and Equipment}

The visual stimuli were six toys from the participants' daily life, and eight toys built with felt. The auditory stimuli were the names of the day-to-day toys (/auau/, /bola/, /carro/, /cubo/, /palhacinho/, /pocotó/), and pseudo-words for the felt toys (/fapi/; /beva/; /daga/; /búgu/; / mido/). The pseudo-words /fapi/ and /beva/ were adopted from the studies of Ribeiro et al. (2016) due to being in harmony with the phonological acquisition typical of the participants' age range (Lamprecht et al., 2004). Three of the felt toys were exposed, butnevernamed. Various toys were employed in the play at the end of the sessions.

The toys were exposed in a "teaching notebook" with adaptation (Almeida, 2014). It consisted of a group of 13 sheets of black stiff card paper, bound with a spiral. Sheets containing three transparent plastic bags for presentation of the objects were interspersed with black pages, which were exposed in the interval between trials. The pages measured $65 \mathrm{~cm}$ wide $\mathrm{x} 35 \mathrm{~cm}$ high, and the transparent plastic bags were $18 \mathrm{~cm}$ wide $\mathrm{x} 24 \mathrm{~cm}$ high, separated by a distance of $3 \mathrm{~cm}$, at $10 \mathrm{~cm}$ from the upper margin and $1 \mathrm{~cm}$ from the lower margin. A Sony ${ }^{\circledR}$ Cyber-Shot DSC W610 14.1MP digital video recorder was used to record the sessions, focusing on the experimenter (female), the participants and the teaching notebook.

\section{Experimental Situation}

The experimental sessions were held in a room of the day-care center with an area of $10 \mathrm{~m}^{2}$, close to the day nurseries.

\section{Procedure}

Data collection. The session had an average duration of four minutes, and took place on average four times a week, over a period between five and eight months. The experimenter (female) and participant remained sitting on the floor, facing each other, with the teaching notebook or the toys between them. When the experimental tasks were completed, there were two minutes of free play (Gil, Oliveira, de Sousa, $\&$ Faleiros, 2006) with toys that were different from the experimental stimuli. Prior to the data collection there was a period of four weeks for familiarization between the researcher (female) and the participants. 
The procedure consisted of three phases: Phase 1 - teaching of baseline conditional discriminations; Phase 2 - teaching of response to the mask, baseline teaching with the mask and control probes; Phase 3 - exclusion and learning probes. Learning was evaluated by three procedures: discrimination probes; learning probes, and naming probes. The criteria of learning from the emerging relations was $100 \%$ success in the discrimination probes. The subsequent learning probes and naming probes were used as additional measures of retention, due to their consistency in the literature of the area (cf. Costa et al., 2014). If the criterion was not achieved, a fourth phase was carried out which consisted of a block of teaching by exclusion (with differential reinforcement) followed by discrimination, naming and learning probes.

A correction procedure was employed for cases of absence of selection response. The sample was spoken every three seconds, for 30 seconds, until the child touched one of the bags. If no response took place, a new trial was initiated. Choices in accordance with the sample were followed by praise and access to the object for approximately 60 seconds. Choices not in accordance with the sample were followed by silence by the researcher and restriction of access to the object. If the participant issued two errors, in selection of the comparison stimuli, the session was ended.

The baseline teaching sessions comprised six trials: success in the trials produced reinforcement in a continuous reinforcement schedule (CRF) or variable-ratio schedule (VR2). The criterion for learning was six successes in six trials; or five successes in six trials, in two consecutive sessions. The blocks of probes were programmed with eight trials, with the exception of the control probe. All the probe trials (control, exclusion, discrimination, learning and naming) were carried out in extinction and the learning criterion was success in all the probe trials of the session.

Phase 1 - Establishment of the conditional discriminations with familiar stimuli (baseline - BL). The trials began with presentation of a sample through the following instruc- tion: "(child's name), pick up the (name of the object)". Then, the comparison stimuli were presented in the learning book (exposure of one, two and three comparison stimuli). Choices (point to, or touch) of the designated stimulus as correct were followed by praise and access to the object for about 60 seconds, in CRF. Incorrect choices were followed by a period of silence by the experimenter where there was restriction of the participant's access to the object, and the start of a new trial. The session was ended if the participant issued two errors distributed over the length of the session.

In the first phase of the teaching each one of the name-object relation were taught separately in sessions in which one sample stimulus and a comparison $(\mathrm{S}+)$ were presented. Immediately following this, the same procedure was carried, but in each trial two comparison stimuli were presented (the S+ and one of the S-'s). Finally, a session was carried out in which the three sample and comparison stimuli alternated over the course of the trials (two trials for each sample). The quantity of comparison stimuli was gradually increased. If the participant did not achieve the criterion in three sessions, the group of stimuli was substituted (/cubo/, /palhacinho/, /pocotó/).

Phase 2 - Teaching of response to the mask. The objective of this phase was to teach the participants to choose the opaque plastic bag, as a blank comparison (Sertori, 2013). The procedure of fading in of the mask was carried out by gradual addition of sheets of semitransparent paper between the plastic bag and the object, making it more opaque over the course of six trials. The teaching was carried out in three sessions of six trials for each stimulus (one sample stimulus and one comparison stimulus), in CRF. The criterion for learning was six successes in six trials.

Teaching of baseline (BL) relations with mask. In this phase the relations taught in Phase 1 were presented in teaching sessions in which the mask was presented as a comparison stimulus. The trials began with presentation of an auditory sample (instruction) and, in the interval of two seconds, the comparison stimuli were 
Table 1

Experimental Design

\begin{tabular}{|c|c|c|c|c|c|c|}
\hline Phases & Task & $\mathrm{N}^{\mathrm{o}}$. of trials & Sample a,b & $\mathrm{N}^{\mathrm{o}}$ of $\mathrm{CoS}$ & $\begin{array}{l}\text { Reinforcement } \\
\text { schedule }\end{array}$ & $\begin{array}{c}\text { Criterion } \\
(\%)\end{array}$ \\
\hline \multirow{3}{*}{$\begin{array}{c}1 \\
\text { Without } \\
\text { mask }\end{array}$} & Baseline & 18 & $\mathrm{D} 1, \mathrm{D} 2, \mathrm{D} 3$ & 1 & $\mathrm{CRF}$ & 100 \\
\hline & Baseline & 6 & D1,D2,D3 & 2 & $\mathrm{CRF}$ & 100 or $83(2 x)$ \\
\hline & Baseline & 6 & D1,D2,D3 & 3 & $\mathrm{CRF}$ & 100 or $83(2 x)$ \\
\hline \multirow{10}{*}{$\begin{array}{c}2 \\
\text { With mask }\end{array}$} & $\begin{array}{l}\text { Teaching of mask } \\
\text { response }\end{array}$ & 18 & D1,D2,D3 & 1 & $\mathrm{CRF}$ & 100 \\
\hline & Baseline & 6 & D1,D2,D3 & 2 & $\mathrm{CRF}$ & 100 or $83(2 x)$ \\
\hline & Baseline & 6 & D1,D2,D3 & 3 & $\mathrm{CRF}$ & 100 or $83(2 x)$ \\
\hline & Baseline & 6 & D1,D2,D3 & 3 & VR2 & 100 or $83(2 x)$ \\
\hline & Probe & & & & & \\
\hline & Baseline & 4 & D1,D2,D3 & 3 & VR2 & 100 \\
\hline & Control & 2 & D1, D3 & 3 & Ext & 100 \\
\hline & Probe & & & & & \\
\hline & Baseline & 4 & D1,D2,D3 & 3 & VR2 & 100 \\
\hline & Control & 2 & I5 & 3 & Ext & 100 \\
\hline \multirow{8}{*}{$\begin{array}{c}3 \\
\text { With mask }\end{array}$} & Probe & & & & & \\
\hline & Baseline & 2 & $\mathrm{D} 1, \mathrm{D} 2, \mathrm{D} 3$ & 3 & CRF & 100 \\
\hline & Exclusion & 2 & I1; I2 & 3 & Ext & 100 \\
\hline & Discrimination & 2 & I1; I2 & 3 & Ext & 100 \\
\hline & Naming & 2 & I1; I2 & & Ext & \\
\hline & Probe & & & & & \\
\hline & Baseline & 2 & D1,D2,D3 & 3 & $\mathrm{CRF}$ & 100 \\
\hline & Learning & 6 & I1;I2;I3;I4 & 3 & Ext & \\
\hline \multirow{9}{*}{$\begin{array}{c}4 \\
\text { With mask }\end{array}$} & Teaching & & & & & \\
\hline & Baseline & 2 & D1, D3 & 3 & VR2 & 100 \\
\hline & Exclusion & 6 & I1; I2 & 3 & $\mathrm{CRF}$ & 100 \\
\hline & Naming & 2 & I1; I2 & & Ext & \\
\hline & Probe & & & & & \\
\hline & Baseline & 1 & D1,D2,D3 & 3 & $\mathrm{CRF}$ & 100 \\
\hline & Discrimination & 2 & I1; I2 & 3 & Ext & 100 \\
\hline & Learning & 6 & I1;I2;I3;I4 & 3 & Ext & \\
\hline & Naming & 2 & I1; I2 & & Ext & \\
\hline
\end{tabular}

Notes. $\mathrm{N}^{\mathrm{o}} \mathrm{Cos}=$ number of comparison stimuli; $\mathrm{CRF}=$ continuous reinforcement; $\mathrm{VR} 2=$ variable ratio 2; $\quad$ Ext=extinction. aDefined stimuli: D1 = auau [dog]; D2 = carro [car]; D3 = bola [ball].

bUndefined stimuli: $\mathrm{I} 1$ = fapi; I2 = beva; $\mathrm{I} 3$ = daga; I4 = búgu; I5 = mido. 
presented in the teaching notebook (two and three comparison stimuli); in all the sessions, the empty comparison (mask) substituted the $\mathrm{S}+$ in one half of the trials. Discrimination between the two relations was taught, in CRF. After the criterion had been achieved, sessions in CRF were presented with the three baseline relationships. After the participant achieved the criterion, a session with a variable ratio 2 schedule was carried out as a preparation for the probes.

Control probes. At the end of the teaching of the baseline a session was held of six trials comprising four baseline trials and two control probe trials. The first control probe evaluated the occurrence of control by novelty. A defined sample of the BL (DS1 or DS3) was presented and the comparison stimuli were: a defined object, a novel undefined object (UC7 or UC8) and the mask. Responses to UC7 or UC8 suggested a control by the novel item. The second control probe verified whether the mask was actually an alternative of choice for the participants. The sample was an undefined word spoken (US5, / mido/) and the comparison stimuli were two defined objects and the mask.

Phase 3 - Exclusion, discrimination, naming and learning probes. The probe sessions comprised eight trials. All the baseline trials were reinforced, while the probes were carried out in extinction. In the first probe session, two baseline trials were presented, two exclusion probes, two discrimination probes between the novel relations, and two naming probes. Success in the exclusion probes was a condition for exposure to the other probes. The second session comprised: two baseline trials, six additional learning probes and two naming probes. The criterion used to attest to occurrence of learning by exclusion was the correct choice in the two discrimination probes of the first session, but, for purposes of comparison, the learning and naming probes were used as additional measures.

Exclusion probes. In the exclusion trials the sample was an undefined word (US1 or US2, /fapi/ or /beva/), and the comparisons were a defined object, and an undefined object (UC1 or UC2) to the mask. Responses to the undefined objects were considered responses by exclusion.
Choices of the mask led to end of the session and holding of a new session in which the mask was replaced by another defined object, to increase the probability of choice of the undefined stimulus and permit evaluation of the learning.

Discrimination probes. The discrimination probes presented the structure originally used by Dixon (1977), in which only the novel stimuli (presented in the exclusion probes) were presented as sample or comparison. In these trials, the sample was one of the two undefined words presented in the exclusion (US1 or US2, /fapi/ or /beva/), and the comparison stimuli were the two undefined objects (UC1 and UC2) and the mask. Choices of the comparison corresponding to the sample would indicate learning.

Naming probes. At the end of the session of discrimination probes, two trials were made, one for each undefined stimulus /fapi/ e /beva/. In these trials, the undefined object was presented by the experimenter accompanied by the instruction: "(name of child), what is its/his name?". The objective was to find out whether the tact responses (Skinner, 1957) relating to the objects would emerge. Responses corresponding point by point with the name of the undefined stimulus (US) were considered correct.

Learning probes. The structure and name of the probes were based on the classification supplied by Costa et al. (2014). The first probe (Type 4) presented as sample the stimulus of the exclusion probe (US1 or US2), and the comparison stimuli where the object chosen in the exclusion probe (UC1 or UC2), a novel object (UC3 or UC4) and the mask. Responses to the stimuli UC1 or UC2 were considered consistent with learning of the relationship of word/figure matching, based on the selection control (sample $-\mathrm{S}+$ relation).

In the second probe carried out (Type 3), the sample stimulus of the exclusion probe was presented (US1 or US2), and the comparison stimuli were a defined stimulus (DC), a second undefined stimulus (UC7 or UC8) and the mask. Responses to the mask were considered indicative of learning. Another learning probe (Type 1) presented a second undefined stimulus as sample (US3 or US4), and the comparison stimuli were 
a defined stimulus (DC), the stimulus chosen in the exclusion probe (UC1 or $\mathrm{UC} 2$ ) and the mask. Selection of the mask suggested rejection of the undefined stimulus chosen in the exclusion probe (supposedly already known on the occasion of the exclusion) and formation of a new relationship (novel name-object). In these probes, the learning of the word/figure matching was demonstrated based on the rejection control (sample $-\mathrm{S}-$ relation).

After this session, if the criterion of learning in the discrimination probes had been achieved, the experiment was terminated for that participant. If not, the procedures of teaching by exclusion were begun (Table 1).

Phase 4 - Teaching by exclusion. The objective of this phase was to verify whether a presentation of reinforcement contingent upon the choices by exclusion would cause learning of the novel auditory-visual relations in children that had not demonstrated it previously (e.g., Carr, 2003). The session of teaching by exclusion comprised 10 trials: two baseline trials, six trials by exclusion, and two naming probes. The baseline trials were conducted in VR2, the trials at teaching by exclusion were in CRF, and the naming trials were in extinction.

A probe session was then immediately held, comprising nine trials: a BL trial (CRF), two discrimination probes and six learning probes (all in extinction). The criteria for learning of the emergent relation was $100 \%$ success in the discrimination probes. If the criterion was achieved, two naming probes were carried out, in extinction. If the criterion was not achieved the teaching sessions by exclusion were held once again, up to the maximum number of three repetitions.

Data analysis. The data were analyzed by calculation of a percentage of correct choices of the participants during the baseline teaching, or on the basis of the parameters described of choices indicative of exclusion or learning, and of control by novelty. The naming responses were analyzed based on the point-to-point correspondence between the participant's verbal response in reaction to the object and the spoken words used as sample.

Agreement between observers. Thirty per cent of the records of the session ( 73 sessions,
337 trials) were analyzed by two independent observers to establish an index of concordance between observers. The calculation was carried out by dividing the number of trials in which there was agreement by the number of agreements plus the number of disagreements, multiplied by 100 (cf. Kazdin, 1982), relating to the participants' choice and responses. The percentage of agreement between the observers was $100 \%$.

Evaluation of the integrity of the behavior of the applier in execution of the procedure. In 73 sessions, two observers examined the compatibility of the behaviors of the applier in relation to the experimental plan, with reference to: instructions to the participants, comparison stimuli presented in each trial, and consequences released related to success or error committed by the participant. The calculation made was the same as for the participants' choice responses (cf. Kazdin, 1982). The percentage of concordance between the observers for the applier's behaviors was $97 \%$.

\section{Ethical Procedures}

The project was approved by the Human Research Ethics Committee of the Federal University of São Carlos (case 1.088.954 of June 9,2015 ), according to the recommendations of Resolution 466/2012. The director (female) of the day-care center authorized carrying out of the research. The participation of the children was authorized by parents or guardians, who signed the Free Consent Form (in Portuguese, 'TCLE'). The parents were informed on the objectives of the research and the tasks that the children would carry out with the researcher.

\section{Results}

In the Denver II Triage Test adapted to Portuguese (Pedromônico et al., 1999), 11 participants presented indications of development risk: three (P3, P6 and P11) in the factor language, three (P1, P5 and P11) in the personal life and social factor and eight (P1, P9, P11, P12, P13, $\mathrm{P} 14, \mathrm{P} 15$ and $\mathrm{P} 16)$ in the gross motor development factor in the initial evaluation. In the final Denver II Triage Test, eight presented indica- 
tions of risk for development: two (P3 and P11) in the language factor and eight (P1, P3, P5, P7, P8, P9, P10 and P11) in the gross motor development factor - see Table 2 . The others presented typical development.

In the initial evaluation of the Inventário Portage Operacionalizado, IPO (Williams \& Aiello, 2001), for the areas of language and cognition there was performance lower than $80 \%$ in relation to the performance estimated by IPO for all the participants. In the final evaluation of IPO, performance remained below $80 \%$ for 16 participants in the area of language $(\mathrm{P} 1, \mathrm{P} 2, \mathrm{P} 3$, P4, P5, P6, P7, P8, P9, P10, P11, P12, P13, P14, $\mathrm{P} 15$ and $\mathrm{P} 16$ ), and for 14 participant in the area of cognition (P1, P2, P3, P4, P5, P6, P7, P8, P9, P10, P11, P12, P13 and P16). However, there was an increase in the score of each one of the participants from the first to the last evaluation, as shown in Table 2.

Six participants (P6, P14, P15, P17, P18 and P19) responded by exclusion. Discrimination probes attested that learning of two name-object relations for three participants (P6, P14 and P19) had taken place. One participant (P17) responded consistently with learning of two relations in the teaching of the name-object relations, after one exclusion probe and three trials similar to the exclusion trial. The participants did not show learning in the additional measures - learning probes (1,3 and 4) and naming probes.

\section{Phase 1 - Establishments of Conditio- nal Discriminations with Familiar Stimuli (baseline - BL)}

Seven of the 19 participants (P5, P6, P14, P15, P17, P18 and P19) achieved the criteria of learning of the three baseline auditory-visual conditional relations. The performance of the participants in the BL trials remained accurate during the other phases of the procedure. All the participants achieved the criterion in the first phase of the baseline training, in which only one sample stimulus was presented. During the teaching with two comparisons, 11 participants achieved the criterion. In the session with three comparisons, four of those 11 participants ( $\mathrm{P} 4$, P8, P9 and P13) did not achieve the criterion.

\section{Phase 2 - Teaching of Response to the Mask and Teaching of the Baseline (BL) Relations with Mask}

All the seven participants (P5, P6, P14, P15, P17, P18 and P19) that reached this phase learned to choose the mask (opaque recipient), in three sessions (each defined stimulus was presented six times). Six participants (except P6) achieved the criterion in the session with two comparison stimuli, and two participants (P14 and P15) did not achieve the criterion of learning for the baseline discriminations with the mask in the sessions with three comparison stimuli, in CRF. One participant (P5) did not achieve the criterion for learning for the session with three comparison stimuli in VR2, and was not exposed to the tests because she had left the day-care center and terminated participation in the study. The participants P6, P14, P15 and P19 were exposed to the probes phase even not having achieved the criterion, because they presented stability in performance and due to the approach of the end of the school year, which would result in the end of the experiment.

\section{Control Probes}

All the participants that reached this stage (P6, P14, P15, P17, P18 and P19) reached the criterion in the control probes, that is to say, they chose the defined object in the trials in which the sample was a defined word of the BL, and the comparison stimuli were the defined object (DC1 or DC3, correct response), one novel undefined object (UC7 or UC8) and the mask. In the trials in which the sample was an undefined spoken word (US5, /mido/) and the comparison stimuli were two defined objects and the mask, all the participants chose the mask.

\section{Phase 3 - Exclusion Probes}

The two trials in this probe were to establish whether the participant selected the undefined objects (UC1 or UC2) when the undefined words (US1, /fapi/ or US2, /beva/) were presented as a sample. Four participants presented the response consistent with the exclusion in the first block for the two novel relations presented. Two par- 


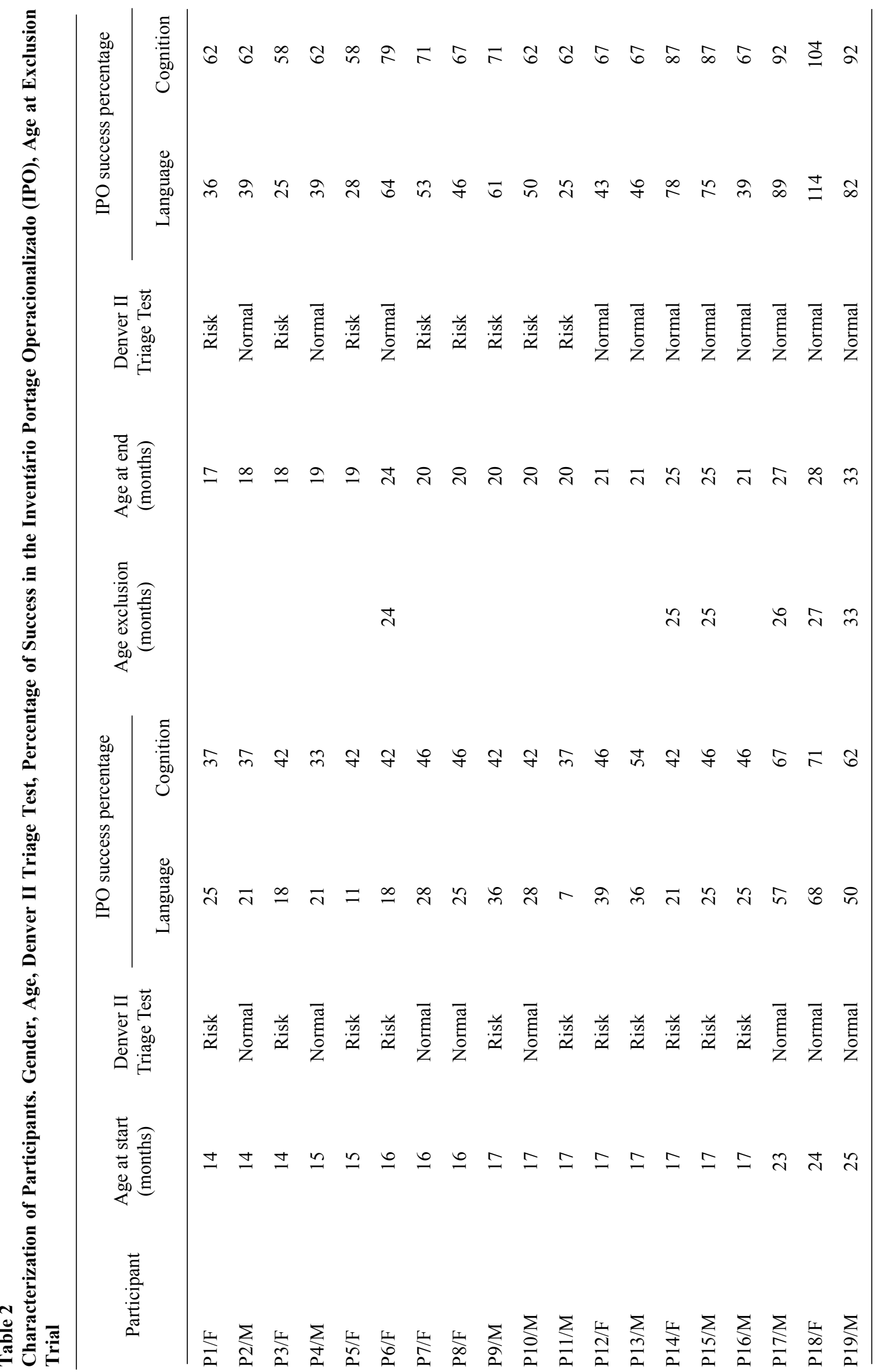


ticipants chose by exclusion only in the second probe. In the first probe carried out, P6 selected the defined stimulus, and P17 selected the mask. A new session was carried out with an exclusion probe for the relation US1-UC1 (comparison stimuli: two defined objects and one undefined object), substituting the mask by a defined object. On that occasion, both the participants achieved the criterion for the US1-UC1 relation (see Table 3).

\section{Discrimination Probes}

The two trials of these probes were to establish whether the participant's choice was under the control of the relations that emerged in the exclusion probe. Three participants, $\mathrm{P} 6, \mathrm{P} 14$ and P19, achieved the learning criterion of the two emergent relations.

\section{Naming Probes}

No participant presented vocalizations corresponding to the sample stimuli presented in the exclusion probes (Table 3 ).

\section{Learning Probes}

Table 3 shows the participants' choices in the three learning probes. No participant demonstrated learning on the basis of these trials, that is to say, chose the correct stimulus in the three types of learning probe. One participant, P17, chose correctly in two types of learning probe for the I1 and I 2 in two types of probes (learning 3 and learning 1). P6 and P19 presented performance consistent with the learning of the US1UC1 relation in two types of probe (learning probes 4 and 1, and 3 and 1, respectively).

\section{Phase 4 - Learning by Exclusion}

Of the two participants that carried out this phase, one participant (P17) achieved the criterion in the two discrimination probes after four exposures to exclusion trials (one exclusion probe and three trials similar to the exclusion trial) for each undefined stimulus (I1 and I2). Participant P18 presented consistent success for the $\mathrm{I} 2$ relation in the three discrimination probes; however she did not reach the learning criterion of the study. In relation to the learning probes (learning
1,3 , and 4), neither of the two participants presented success in the three probes in one single session.

In the naming probes participant $\mathrm{P} 17$ issued the verbalization /beca/ when presented with stimuli I1 and I 2 after the first teaching by exclusion, and issued the verbalizations /atata/ for I1 and /uataki/ for I2 after the probes. The participant P18 issued the verbalizations for I1 and I2, respectively: /pafi/ and /beco/ after the first teaching; / eu não sei/ and/beva/ after the second teaching; and /é beva/ and /é beva/ after the third teaching.

\section{Discussion}

The objective of the study was to evaluate, in children aged 14 to 25 months, learning by exclusion of relations between names and objects employing discrimination probes. Additionally, it aimed to compare the performance of the participants in the discrimination probes with the performance in the learning and naming probes. In this study, of the 19 participants that began the experiment, two achieved the baseline criterion and carried out the probe stages. Four participants (P6, P14, P15 and P19) presented stable performance (even though they had not achieved the baseline learning criteria), and carried out the probe phases. Of the eight participants who did not achieve baseline criterion during the teaching with two comparison stimuli, three presented choice by preference for a specific stimulus (P2: D3; P11: D6; and P16: D3) and four presented preference for a specific position (P1 and $\mathrm{P} 2$ : left; $\mathrm{P} 3$ and P16: right). Of the four participants who did not achieve criterion in the teaching with the three comparison stimuli, three participants presented a preference for one stimulus (P4: D6; P9: D3 and P13: D3) and one participant responded under control by position (P13: center). The establishment of control of stimuli by characteristics that were irrelevant to the experimental arrangement, to the detriment of the control of stimuli programmed by the experimenter, appears to have produced the children's performance in teaching of the baseline relationships (Dube \& McIlvane, 1996). 
Table 3

Participants' Choices in the Exclusion, Discrimination, Naming and Learning Probes

\begin{tabular}{|c|c|c|c|c|c|c|c|c|c|}
\hline \multirow[t]{3}{*}{ Part. } & \multicolumn{3}{|c|}{ Exclusion } & \multicolumn{3}{|c|}{ Discrimination } & \multicolumn{3}{|c|}{ Naming } \\
\hline & \multicolumn{3}{|c|}{ Undefined 1} & \multicolumn{3}{|c|}{ Undefined 1} & \multicolumn{3}{|c|}{ Undefined 1} \\
\hline & Und1 & Def & $\mathrm{M}$ & Und1 & Und2 & M & \multicolumn{3}{|c|}{ /Fapi/ } \\
\hline P6 & 1 & 1 & 0 & 1 & 0 & 0 & \multicolumn{3}{|c|}{-} \\
\hline P14 & 1 & 0 & 0 & 1 & 0 & 0 & \multicolumn{3}{|c|}{-} \\
\hline P15 & 1 & 0 & 0 & 1 & 0 & 0 & \multicolumn{3}{|c|}{ /beu/ } \\
\hline P17 & 1 & 0 & 1 & 0 & 1 & 0 & \multicolumn{3}{|c|}{ /uáu/ } \\
\hline P18 & 1 & 0 & 0 & 1 & 0 & 0 & \multicolumn{3}{|c|}{ lé, eu não seil } \\
\hline \multirow[t]{3}{*}{ P19 } & 1 & 0 & 0 & 1 & 0 & 0 & & - & \\
\hline & \multicolumn{3}{|c|}{ Undefined 2} & \multicolumn{3}{|c|}{ Undefined 2} & \multicolumn{3}{|c|}{ Undefined 2} \\
\hline & Und2 & Def & $\mathrm{M}$ & Und2 & Und1 & $\mathrm{M}$ & \multicolumn{3}{|c|}{ /Beva/ } \\
\hline P6 & 1 & 0 & 0 & 1 & 0 & 0 & \multicolumn{3}{|c|}{ - } \\
\hline P14 & 1 & 0 & 0 & 1 & 0 & 0 & \multicolumn{3}{|c|}{ /be/ } \\
\hline P15 & 1 & 0 & 0 & 0 & 1 & 0 & \multicolumn{3}{|c|}{ /beu/ } \\
\hline P17 & 1 & 0 & 0 & 0 & 1 & 0 & \multicolumn{3}{|c|}{ /uél } \\
\hline P18 & 1 & 0 & 0 & 0 & 0 & 1 & \multicolumn{3}{|c|}{ leu não sei, é/ } \\
\hline P19 & 1 & 0 & 0 & 1 & 0 & 0 & \multicolumn{3}{|c|}{ - } \\
\hline \multirow[t]{3}{*}{ Part. } & \multicolumn{3}{|c|}{ Learning 4} & \multicolumn{3}{|c|}{ Learning 3} & & rning & \\
\hline & & idefinec & & & Idefinec & & & lefine & \\
\hline & Und1 & Und 3 & M & M & Def & Und7 & M & Def & Und1 \\
\hline P6 & 1 & 0 & 0 & 0 & 0 & 1 & 1 & 0 & 0 \\
\hline P14 & 1 & 0 & 0 & 0 & 0 & 1 & 0 & 0 & 1 \\
\hline P15 & 1 & 0 & 0 & 0 & 0 & 1 & 0 & 1 & 0 \\
\hline P17 & 0 & 1 & 0 & 1 & 0 & 0 & 1 & 0 & 0 \\
\hline P18 & 0 & 1 & 0 & 0 & 0 & 1 & 1 & 0 & 0 \\
\hline P19 & 0 & 1 & 0 & 1 & 0 & 0 & 1 & 0 & 0 \\
\hline & & idefinec & & & Idefinec & & & lefine & \\
\hline & Und2 & Und 4 & $\mathrm{M}$ & M & Def & Und8 & M & Def & Und2 \\
\hline P6 & 0 & 1 & 0 & 0 & 1 & 0 & 0 & 1 & 0 \\
\hline P14 & 0 & 1 & 0 & 0 & 0 & 1 & 0 & 0 & 1 \\
\hline P15 & 0 & 1 & 0 & 0 & 0 & 1 & 0 & 1 & 0 \\
\hline P17 & 0 & 0 & 1 & 1 & 0 & 0 & 1 & 0 & 0 \\
\hline P18 & 0 & 1 & 0 & 0 & 0 & 1 & 0 & 0 & 1 \\
\hline P19 & 1 & 0 & 0 & 0 & 1 & 0 & 0 & 1 & 0 \\
\hline
\end{tabular}

Notes. Numbers in bold represent the right choice for each probe. Part.= participant. Def.= defined stimulus; Ind.= undefined stimulus; $\mathrm{M}=$ mask. $(-)$ = absence of naming. 
The six participants that presented stability in the baseline performance obtained $100 \%$ success in the control probes, attesting to the stability of the discriminations taught. This result is important, because it reduces the possibility that participants' choices in the subsequent probes be interpreted only on the basis of control by novelty of stimuli. In the exclusion probes, regular occurrence of response by exclusion was observed for the six participants, aged between 24 and 33 months, results consistent with those indicated by literature (e.g., Antoniazzi et al., 2014; Barbosa et al., 2015; Costa et al., 2013; Costa et al., 2001; Dixon, 1977; Domeniconi et al., 2007; Ribeiro \& Schmidt, 2015; Ribeiro et al., 2016; Schmidt et al., 2016; Wilkinson \& McIlvane, 1997). As well as the consistent response in the choice of the undefined object when presented with the undefined name, the response by exclusion was also consistently observed in the other type of control probes, in which no undefined stimulus was presented and the exclusion of the defined stimuli would result in selection of the mask (opaque plastic bag).

In relation to the evaluation of learning, the initial hypothesis was that the use of discrimination probes could increase the probability of performances consistent with learning after only one choice by exclusion, when compared to the other measures. The choice in the discrimination probes was carried out between the undefined relations emerging by exclusion, with the absence of novel stimuli or distracting factors present in the traditional learning probes. As observed, three participants (P6, P14 and P19) achieved the criterion in the discrimination probes, while none of them achieved the criterion in the traditional learning probes (success in all the three probes, namely learning 1, 3 and 4). It is important to highlight that in the exposure to the exclusion probe and discrimination probes, the participants were aged 24, 25 and 33 months, respectively, eight months more than they had at the beginning of the teaching of baseline relations.

Two participants (P17 and P18) carried out the teaching by exclusion phase and presented success for all the trials similar to the exclu- sion trial. One participant (P17), at the time 27 months old, achieved criterion in the discrimination stages after one exclusion trial and three trials similar to the exclusion trial. Participant P18, aged 28 months, succeeding in the three discrimination probe trials for the relation I2 / beva/, which suggests learning for only one relation (I2).

The results indicate that the discrimination probes, carried out after the trials at response by exclusion (de Rose et al., 1996; de Rose et al., 1989; Dixon, 1977; Mcllvane \& Stoddard, 1981), presented themselves as a viable alternative for measuring learning of emergent conditional discrimination. It is important to point out that the parameters that permitted choice by exclusion are not presented in these trials (baseline defined comparisons). Even so, the four participants (P6, P14, P17 and P19) responded correctly to the discrimination probes, indicating the acquisition of a novel name-object relation without prior teaching.

At the same time, according to the analysis made by Costa et al. (2014), in a computation of the performance of all the participants below 36 months old, 10 (9.7\%) of 103 children presented results indicative of learning (success in the three probes 1, 2 and 3, or probes 4,3 and 1 of learning): these figures were the total of the following results in the following studies: in the study of Domeniconi et al. (2007), one in six participants; in the study by Antoniazzi et al. (2014), one in 10 participants; in the study by Barbosa et al. (2015), one in 10 participants; in the study by Ribeiro et al. (2016), one in 21 participants; and in the study by Schmidt et al. (2016), six in 56 participants. Overall, the participants presented success in one or two probes (e.g., Ribeiro et al., 2016; Schmidt et al., 2016). This pattern was also observed in this study, by replicating the results found in the literature and expanding the sample of participants. The rate of successes in each probes, in Phase 3, was $41 \%$ for learning $1,25 \%$ for learning 3 and $33 \%$ for learning 4 , indicating better performance in the control by rejection. The analysis of the patterns of error in these probes indicated that seven of the nine errors presented in learning probe 3 referred to 
the choice of the newest undefined object (Undefined 7 or Undefined 8). Similarly, seven of the eight errors in the learning 4 probes were choices of Undefined 3 or Undefined 4. Similar results were observed in other studies with children of the same age (e.g., Ribeiro de Souza et al., 2018; Schmidt et al., 2016) and corroborated the evidence that control by novelty exerts influence on the patterns of choice of children in analogous tasks (Horst et al., 2011).

Even though four participants (P6, P14, P17 and $\mathrm{P} 19)$ presented learning of the emergent relationships by exclusion, the learning of the auditory-visual conditional relations was not a sufficient condition for the participants to name the objects. In the naming probes (tact responses, Skinner, 1957), no participant named the stimuli. And for those that did name them, there was not a sufficient condition to precisely specify the topography in the naming. In the naming the control demanded is for the relationship between the word spoken and the object, with the object present. The two words relating to the emergent relations shared multiple differences (differences between more than half of the phonemes), and the objects shared multiple differences (colors and format), instead of words and objects with critical differences, which could increase the degree of complexity of the task (Souza, AlmeidaVerdu, \& Belivacqua, 2013). Participants P17 and $\mathrm{P} 18$ presented partially corresponding verbalizations in sessions of teaching of the emergent name-object relations (P17 said: /beca/ for I2; /pafi/ for I1; and P18 said: /beco/ for I2). These results are confirmed by the literature: the speech, especially of small children, does not correspond, or corresponds only partially, to the sample-word (Costa et al., 2014). Future studies could investigate whether, and under what conditions, the naming probes can help to monitor the control relations present in the learning of the emergent relations by exclusion.

The results suggest that the discrimination probes may serve to make up a proposal for evaluation of learning by exclusion that is less subject to the interferences of other sources of control (comparison stimuli of the relationships that emerged in the exclusion, without the presence of novel or distracting stimuli, as happens in traditional learning probes). However, further studies need to be made to ensure the reliability of the procedure. It is important to point out that the number of probes used in this study was comparatively low in relation to prior studies (de Rose et al., 1996; de Rose et al., 1989; Dixon, 1977; McIlvane \& Stoddard, 1981). Consequently, future studies should employ a larger number of trials to evaluate learning, to reduce the possibility that the performances observed take place by chance. Additionally, considering the rapid changes in the repertoire of the participants at this age range, an increase in the score of each one of the participants was observed from the first to the last IPO evaluation, as was also observed a reduction of participants with an indication of development risk in the Denver II; future investigations should also evaluate whether the instruments used have shown themselves to be predictors of the results produced by the participants.

\section{References}

Almeida, C. G. M. (2014). Novos repertórios verbais em crianças pequenas: ouvinte, falante e classes de estímulos equivalentes [New verbal repertoire in toddlers: Listener, speaker and stimulus class formation]. (Doctoral dissertation). Retrieved from https://repositorio.ufscar.br/handle/ ufscar/5995

Antoniazzi, M., Domeniconi, C., \& Schmidt, A. (2014). Efeito da pré-exposição ao objeto no desempenho por exclusão e na aprendizagem da relação nome-objeto [Effect of object preexposure on exclusion performance and nameobject relation learning]. Acta Comportamentalia, 22(1), 23-36. Retrieved from http://pepsic. bvsalud.org/scielo.php?script=sci_arttext\&pid $=\mathrm{S} 0188-81452014000100003 \& \operatorname{lng}=\mathrm{pt} \& \mathrm{t} \operatorname{lng}=\mathrm{pt}$

Barbosa, B. F., Gomes, G. F., Costa, A. R. A., \& Schmidt, A. (2015). Aprendizagem de discriminação auditivo-visual a partir de uma única tentativa de exclusão com objetos tridimensionais [Learning auditory-visual discrimination from a single exclusion trial with three-dimensional objects]. Revista Brasileira de Terapia Com- 
portamental e Cognitiva, 17(3), 22-37. Retrieved from http://www.usp.br/rbtcc/index.php/ RBTCC/article/view/813

Bion, R. A. H., Borovsky, A., \& Fernald, A. (2013). Fast mapping, slow learning: Disambiguation of novel word-object mappings in relation to vocabulary learning at 18,24 , and 30 months. Cognition, 126, 39-53. doi: https://doi.org/10.1016/j. cognition.2012.08.008

Bluma, S., Shearer, M., Frohman, A., \& Hilliard, J. (1976). Portage guide to early education. Portage, WI: Cooperative Educational Service Agency.

Carr, D. (2003). Effects of exemplar training in exclusion responding on auditory-visual discrimination tasks with children with autism. Journal of Applied Behavior Analysis, 36, 507-524. doi: 10.1901/jaba.2003.36-507

Costa, A. R. A., Domeniconi, C., \& de Souza, D. G. (2014). Controle de estímulos, mapeamento simbólico emergente e aquisição de vocabulário [Stimulus control, symbolic emergent mapping, and vocabulary acquisition]. In J. C. de Rose, M. S. C. A. Gil, \& D. G. de Souza (Eds.), Comportamento simbólico: Bases conceituais e empiricas (pp. 269-308). Marília, SP: Oficina Universitária.

Costa, A. R. A., Grisante, P. C., Domeniconi, C., de Rose, J. C., \& de Souza, D. G. (2013). Naming new stimuli after selection by exclusion. Paidéia (Ribeirão Preto), 23(55), 217-224. doi: 10.1590/1982-43272355201309

Costa, A. R. A., Wilkinson, K. M., McIlvane, J. W., \& de Souza, D. G. (2001). Emergent word object mapping by children: Further studies using the blank comparison technique. The Psychological Record, 51(3), 343-355. Retrieved from http://opensiuc.lib.siu.edu/cgi/viewcontent. cgi? article $=1321 \&$ context $=$ tpr

De Rose, J. C., de Souza, D. G., \& Hanna, E. S. (1996). Teaching reading and spelling: Exclusion and stimulus equivalence. Journal of Applied Behavior Analysis, 29, 451-469. doi: 10.1901/jaba.1996.29-451

De Rose, J. C., de Souza, D. G., Rossito, A. L., \& de Rose, T. M. S. (1989). Aquisição de leitura após história de fracasso escolar: Equivalência de estímulos e generalização [Reading acquisition after a history of academic failure: Stimulus equivalence and generalization]. Psicologia:
Teoria e Pesquisa, 5(3), 325-346. Retrieved from https://revistaptp.unb.br/index.php/ptp/article/view/1384/376

Dixon, L. S. (1977). The nature of control by spoken words over visual stimulus selection. Journal of the Experimental Analysis of Behavior, 27(3), 433-442. doi: 10.1901/jeab.1977.27-433

Domeniconi, C., Costa, A. R. A., de Souza, D. G., \& de Rose, J. C. (2007). Responder por exclusão em crianças de 2 a 3 anos em uma situação de brincadeira [Exclusion responding by 2 to 3 yearold children in a play setting]. Psicologia: Reflexão e Crítica, 20(2), 342-350. doi: 10.1590/ S0102-79722007000200021

Dube, W. V., \& McIlvane, W. J. (1996). Some implications of a stimulus control topography analysis for emergent stimulus classes. In T. R. Zentall \& P. M. Smeets (Eds.). Stimulus class formation in humans and animals (pp. 197-218). North-Holland, Netherlands: Elsevier.

Frankenburg, K.W., Dodds, J., Archer, P., \& Bresnick, B. (1990). Denver II: Technical manual. Denver, CO: Denver Developmental Materials.

Gil, M. S. C. A., Oliveira, T. P., de Sousa, N. M., \& Faleiros, D. A. M. (2006). Variáveis no ensino de discriminação para bebês [Variables in teaching of infants discrimination]. Psicologia: Teoria e Pesquisa, 22(2), 143-152. doi: 10.1590/ S0102-37722006000200003

Greer, R. D., \& Du, L. (2015). Experience and the onset of the capability to learn names incidentally by exclusion. The Psychological Record, 65(2), 355-373. doi: 10.1007/ s40732-014-0111-2

Horst, J. S., \& Samuelson, L. K. (2008). Fast mapping but poor retention by 24-monthold infants. Infancy, 13(2), 128-157. doi: $10.1080 / 15250000701795598$

Horst, J. S., Samuelson, L. K., Kucker, S. C., \& McMurray, B. (2011). What's new? Children prefer novelty in referent selection. Cognition, 118(2), 234-244. doi: 10.1016/j.cognition.2010.10.015

Kazdin, A. E. (1982). Single-case research designs: Methods for clinical and applied settings. New York: Oxford University Press.

Lamprecht, R. R., Bonilha, G. F. G., Freitas, G. C. M., Matzenauer, C. L. B. Mezzomo, C. L., Oliveira, C. C., \& Ribas, L. P. (2004). Aquisição Fonológica do Português: Perfil de desenvolvimento e subsidios para terapia [Phonological acquisi- 
tion of Portuguese: Developmental profile and subsidies for therapy]. São Paulo, SP: Artmed.

Langsdorff, L. C., Schmidt, A., \& Domeniconi, C. (2015). Aprendizagem de relações auditivovisuais por meio de tentativas de exclusão [Auditory-visual relationship learning by exclusion trials]. Interação em Psicologia, 19, 25-35. doi: 10.5380/psi.v19i1.33978

McIlvane, W. J., \& Stoddard, T. (1981). Acquisition of matching to sample performances in severe retardation: Learning by exclusion. Journal of Mental Deficiency Research, 25, 33-48.

Pedromônico, M. R. N., Bragatto, E. L., \& Strobilus, R. (1999). Teste de Triagem Denver II [Denver Developmental Screening Test II]. São Paulo, SP: Universidade Federal de São Paulo.

Ribeiro, T. A., Gallano, T. P., Souza, D. H., \& de Souza, D. G. (2016). Responding and Learning by Exclusion in 2-Year-Olds: The Case of Adjectives. The Psychological Record, 1, 1-22. doi: 10.1007/s40732-016-0213-0

Ribeiro de Souza, L. M., Gil, M. S. C. A., \& Garcia, L. T. (2018). Aprendizagem por exclusão em crianças pequenas. Paidéia (Ribeirão Preto), 28, e2810. doi: http://dx.doi.org/10.1590/1982$4327 \mathrm{e} 2810$

Ribeiro de Souza, L. M., Minto de Sousa, N., \& Gil, M. S. C. A. (2016). Aprendizagem de relações emergentes por exclusão em crianças de 2 a 3 anos [Learning emergent relations by exclusion in 2 to 3 years-old children]. Revista Brasileira de Análise do Comportamento, 12, 44-53. doi: http://dx.doi.org/10.18542/rebac.v12i1.3788

Ribeiro, J., \& Schmidt, A. (2015). Aprendizagem de relações palavra-objeto por bebês em um procedimento de introdução sucessiva de estímulos [Learning of word-object relations in infants in a successive introduction of stimulus procedure]. Revista Brasileira de Análise do Comportamento, 11(1), 70-79. doi: 10.18542/rebac. v11i1.3777

Schmidt, A., Franco, M. G. O., Lotério, L. S., \& Gomes, G. F. (2016). Learning name-object relations after a single exclusion trial in 18to 48-month-old children. The Psychological Record, 66, 53-63. doi: 10.1007/s40732-0150151-2

Sertori, N. M. (2013). Discriminações condicionais em bebês de risco: $O$ responder por exclusão [Conditional discrimination in infants at risk: Exclusion responding]. (Master's thesis). Retrieved from https://repositorio.ufscar.br/handle/ ufscar/3143

Skinner, B. F. (1957). Verbal Behavior. New York: Appleton-Century-Crofts.

Souza, F. C., Almeida-Verdu, A. C. M., \& Bevilacqua, M. C. (2013). Ecoico e nomeação de figuras em crianças com deficiência auditiva pré-lingual com implante coclear [Echoic and picture naming in prelingual impaired hearing children with cochlear implant]. Acta Comportamentalia, 21(3), 325-339. Retrieved from http:// www.revistas.unam.mx/index.php/acom/article/ view/41749

Wilkinson, K. M., Dube, W. V., \& McIlvane, W. J. (1998). Fast mapping and exclusion (emergent matching) in developmental language, behavior analysis, and animal cognition research. The Psychological Record, 48, 407-422. doi: 10.1007/BF03395281

Wilkinson, K. M., \& McIlvane, W. J. (1997). Blank comparison analysis of emergent symbolic mapping by young children. Journal of Experimental Child Psychology, 67(2), 115-130. doi: 10.1006/jecp.1997.2402

Williams, L. C. A., \& Aiello, A. L. R. (2001). $O$ Inventário Portage Operacionalizado: Intervenção com famílias [The Inventário Portage Operacionalizado: Intervention with families]. São Paulo, SP: Memnon.

Received: $17 / 11 / 2017$

$1^{\text {st }}$ revision: $11 / 02 / 2018$

$2^{\text {nd }}$ revision: $14 / 02 / 2018$

Accepted: 14/02/2018

(cc) BY 1 (C) The Author(s), 2018. Open Access. This article is distributed under the terms of the Creative Commons Attribution 4.0 International License (http://creativecommons.org/licenses/by/4.0/), which permits unrestricted use, distribution, and reproduction in any medium, provided you give appropriate credit to the original author(s) and the source, provide a link to the Creative Commons license, and indicate if changes were made. 